\title{
Comparative decline in funding of European Commission malaria vaccine projects: what next for the European scientists working in this field?
}

Regitze L Thøgersen ${ }^{1 *}$, Anthony A Holder ${ }^{2}$, Adrian VS Hill ${ }^{3}$, David E Arnot ${ }^{4}$, Egeruan B Imoukhuede ${ }^{1}$ and Odile Leroy ${ }^{1}$

\begin{abstract}
Since 2000, under the Fifth and subsequent Framework Programmes, the European Commission has funded research to spur the development of a malaria vaccine. This funding has contributed to the promotion of an integrated infrastructure consisting of European basic, applied and clinical scientists in academia and small and medium enterprises, together with partners in Africa. Research has added basic understanding of what is required of a malaria vaccine, allowing selected candidates to be prioritized and some to be moved forward into clinical trials. To end the health burden of malaria, and its economic and social impact on development, the international community has now essentially committed itself to the eventual eradication of malaria. Given the current tentative advances towards elimination or eradication of malaria in many endemic areas, malaria vaccines constitute an additional and almost certainly essential component of any strategic plan to interrupt transmission of malaria. However, funding for malaria vaccines has been substantially reduced in the Seventh Framework Programme compared with earlier Framework Programmes, and without further support the gains made by earlier European investment will be lost.
\end{abstract}

\section{Background}

Approximately one million people die each year from malaria, mostly African children under the age of five and pregnant women [1,2]. Malaria is, therefore, one of the major global killer diseases and one of the world's biggest public health problems $[1,3]$. As malaria is mainly prevalent in low-income countries, it places a disproportionately heavy economic burden on endemic countries, contributing to poverty and limiting economic development $[1,4]$.

Malaria is a complex disease, which is transmitted to humans through the bite of the female Anopheles mosquito inoculating protozoan parasites of the genus Plasmodium. There are five types of human malaria, Plasmodium falciparum, Plasmodium vivax, Plasmodium malariae, Plasmodium ovale, and Plasmodium knowlesi, with

\footnotetext{
* Correspondence: regitze.thoegersen@euvaccine.eu ${ }^{1}$ European Vaccine Initiative, UniversitätsKlinikum Heidelberg, Im Neuenheimer Feld 326, 69120 Heidelberg, Germany

Full list of author information is available at the end of the article
}

$P$. falciparumand $P$. vivax being the most common and P. falciparum being the most deadly $[1,2]$.

A protective malaria vaccine that prevents or reduces clinical malaria and associated mortality, as well as reducing transmission, will have a major impact on global human health and socioeconomic development. There is considerable optimism that a malaria vaccine can be developed, as immunity developed following natural infection eventually prevents mortality and protects against clinical disease [3].

A malaria vaccine developed by GlaxoSmithKline (GSK) is being tested in various African countries in Phase III clinical trials, following earlier relatively promising results indicating that perhaps $40-50 \%$ of immunized children were protected against natural infection for a significant period [5]. However, it seems unlikely that GSK's RTS, S pre-erythrocytic stage vaccine will generate higher levels of protection in Phase 
III clinical trials than those achieved in Phase II clinical trials and it is doubtful whether the RTS, S vaccine will have any impact on reducing malaria transmission. To achieve elimination and eventual eradication, it is clearly necessary to intensify the research and development effort to obtain more protective, longer lasting malaria vaccines, including vaccines which also protect against other species of malaria, particularly the very widely transmitted $P$. vivax.

\section{History of European Commission funded malaria vaccine projects}

Under the Fifth Framework Programme (FP) plan for Research and Technology Development (1998-2002), the European Commission (EC) funded a broad range of research activities related to the three major poverty-related diseases (PRDs), HIV/AIDS, malaria and tuberculosis. A total of 24 malaria projects were supported in this period, with a total budget of approximately $€ 29$ million, of which around $€ 17$ million was dedicated to malaria vaccine projects $[1,6]$. Increased funding for PRD research was provided in FP6 (20022006) and a portfolio of 17 malaria projects was established, with an overall budget of about $€ 64$ million, of which almost $€ 20$ million was dedicated to malaria vaccine projects [1].

In the current FP7 plan, (2007-2013), efforts were made to capitalize on the advances achieved under FP6 by improved integration of basic malaria research with more robust research and management structures to translate research results into therapeutic drugs or vaccine candidates. By the end of 2010, halfway through the FP7, a total of nearly $€ 80$ million was earmarked for malaria research. However, only around $€ 10$ million was earmarked for malaria vaccine research [1]. This probably reflected optimism that the GSK RTS, S vaccine would translate well into the developing global anti-malaria campaign and fuelled suggestions that improved vaccines were not a priority.

The past and present EC funded malaria vaccine projects under FP5, FP6 and FP7 are listed in Table 1, 2 and 3 respectively [1].

\section{Key successes, their impact and future perspectives}

Vaccines are one of the most effective ways to protect people against infectious diseases, and one of the most cost-effective measures of public health. A malaria vaccine is unlikely to be developed if not supported by public sector and charitable funding and international public organizations, such as the EC [7].

Useful and significant advances have already been achieved by several malaria vaccine projects funded by the EC. A number of its malaria vaccine development projects are in the clinical testing process and will report in the next period. Current EC strategies clearly complement those of other international agencies in this area and have the potential to make a major impact on malaria vaccine development projects. It is, therefore, critical that the EC continues to build on the major advances in understanding immunity to malaria that have been achieved and on several successes in raising immunogenicity of candidate vaccines. Rather than abandon this field, mechanisms for continuing to develop more effective malaria vaccines by building on the current RTS, S successes should be established [7].

\section{Conclusions}

To maintain and consolidate the European vaccine development infrastructure and exploit the considerable depth of European expertise in this area, continued funding for malaria vaccine research is essential. Doing otherwise will ensure that European vaccine R\&D teams, in both

Table 1 Malaria vaccine projects funded by the EC FP5

\begin{tabular}{|c|c|c|c|c|c|c|}
\hline $\begin{array}{l}\text { Project } \\
\text { Acronym }\end{array}$ & $\begin{array}{l}\text { Project } \\
\text { Type }\end{array}$ & $\begin{array}{l}\text { Coordinator } \\
\text { Name/Institution }\end{array}$ & $\begin{array}{l}\text { Partner } \\
\text { Numbers }\end{array}$ & $\begin{array}{l}\text { EC Contribution } \\
\text { Euros }\end{array}$ & $\begin{array}{l}\text { Duration } \\
\text { Months }\end{array}$ & $\begin{array}{l}\text { Start } \\
\text { Date }\end{array}$ \\
\hline EUROMALVAC1 & RS & D. Arnot, University of Edinburgh, UK & 10 & 3500000 & 36 & $01-02-2000$ \\
\hline ATTMAL & RS & A. Waters, Leiden University, NL & 5 & 1492640 & 36 & $01-03-2000$ \\
\hline MALTRANS & RS & R. Sauerwein, Radboud University Nijmegen Medical Centre, NL & 11 & 2499962 & 36 & $01-03-2000$ \\
\hline AMVTNETHIC & AM & S. Jepsen, Statens Serum Institut, DK & 1 & 220000 & 36 & $01-04-2000$ \\
\hline PAMVAC & RS & M. Klinkert, Bernhard-Nocht-Institute for Tropical Medicine, DE & 6 & 1503210 & 36 & 01-09-2001 \\
\hline NEMLAR & $\mathrm{AM}$ & S. Jepsen, Statens Serum Institut, DK & 1 & 70000 & 36 & $01-12-2001$ \\
\hline EMLI & DM & P. Druilhe, Institut Pateur, FR & 7 & 1462733 & 36 & $01-01-2002$ \\
\hline EMVI & AM & S. Jepsen, Statens Serum Institut, DK & 2 & 700000 & 36 & 01-08-2002 \\
\hline EUROMALVAC2 & RS & D. Arnot, University of Edinburgh, UK & 12 & 3700044 & 36 & 01-09-2002 \\
\hline VIRIMAL & RS & P. Preiser, Medical Research Council, UK & 5 & 1196180 & 36 & 01-09-2002 \\
\hline AMVTN/AMANET & CA & S. Jepsen, Statens Serum Institut, DK & 16 & 1000000 & 36 & 01-11-2002 \\
\hline \multicolumn{4}{|c|}{ Total EC contribution under FP5 } & 17344769 & & \\
\hline
\end{tabular}

AM: Accompanying Measures, CA: Coordination Action, DM: Demonstration, RS: Research 
Table 2 Malaria vaccine projects funded by the EC FP6

\begin{tabular}{lllllll}
\hline $\begin{array}{l}\text { Project } \\
\text { Acronym }\end{array}$ & $\begin{array}{l}\text { Project } \\
\text { Type }\end{array}$ & $\begin{array}{l}\text { Coordinator } \\
\text { Name/Institution }\end{array}$ & $\begin{array}{l}\text { Partner } \\
\text { Numbers }\end{array}$ & $\begin{array}{l}\text { EC Contribution } \\
\text { Euros }\end{array}$ & $\begin{array}{l}\text { Duration } \\
\text { Months }\end{array}$ & $\begin{array}{l}\text { Start } \\
\text { Date }\end{array}$ \\
\hline MALINV & STREP & L. Rénia, Département d'Immunologie, Institut Cochin, FR & 5 & 587000 & 24 & $01-06-2005$ \\
SME Malaria & STREP & R. Glück, Etna Biotech, IT & 5 & 1700000 & 36 & $01-03-2006$ \\
EMVDA & IP & O. Leroy, European Vaccine Initiative, DE & 15 & 13500000 & 63 & $01-12-2006$ \\
EURHAVAC & SSA & O. Leroy, European Malaria Vaccine Initiative, DK & 1 & 260000 & 24 & $01-12-2006$ \\
CILMALVAC & STREP & M. Hartmann, Cilian AG, DE & 3 & 1271664 & 36 & $01-01-2007$ \\
PRIBOMAL & STREP & J. Goudsmit, Crucell Holland, NL & 7 & 2345358 & 48 & $01-02-2007$ \\
\hline
\end{tabular}

Total EC contribution under FP6

19664022

IP: Integrated Project, SSA: Specific Support Actions, STREP: Specific Targeted Research Project.

Table 3 Malaria vaccine projects funded by the EC FP7

\begin{tabular}{|c|c|c|c|c|c|c|}
\hline $\begin{array}{l}\text { Project } \\
\text { Acronym }\end{array}$ & $\begin{array}{l}\text { Project } \\
\text { Type }\end{array}$ & $\begin{array}{l}\text { Coordinator } \\
\text { Name/Institution }\end{array}$ & $\begin{array}{l}\text { Partner } \\
\text { Numbers }\end{array}$ & $\begin{array}{l}\text { EC Contribution } \\
\text { Euros }\end{array}$ & $\begin{array}{l}\text { Duration } \\
\text { Months }\end{array}$ & $\begin{array}{l}\text { Start } \\
\text { Date } \\
\end{array}$ \\
\hline PreMalStruct & S/M-SFRP & B. Gamain, Institut Pasteur, FR & 5 & 2300000 & 36 & $01-02-2008$ \\
\hline STOPPAM & S/M-SFRP & M. Laurent, Institut de Recherche Pour le Development, FR & 6 & 3000000 & 36 & $01-02-2008$ \\
\hline INYVAX & CA & O. Leroy, European Vaccine Initiative, DE & 7 & 932335 & 36 & 01-02-2009 \\
\hline OPTIMALVAC & $C A$ & O. Leroy, European Vaccine Initiative, DE & 12 & 1000000 & 36 & 01-04-2009 \\
\hline REDMAL & FRP & R. Sauerwein, Radboud University Nijmegen Medical Centre, NL & 6 & 2999998 & 48 & 01-03-2010 \\
\hline
\end{tabular}

Total EC contribution under FP7

10232333

CA: Coordination Action, S/M-SFRP: Small or medium-scale focused research project.

industry and academia, will be forced to disband and Europe risks becoming irrelevant in the global push to eliminate malaria, just as this campaign gathers momentum.

\section{Acknowledgements and funding}

The EMVDA project has been funded by the EC FP6 HEALTH (LSHP-CT-2007037). We would like to thank the EMVDA Consortium for their work and contribution: Odile Leroy, European Vaccine Initiative, Germany; Rinaldo Zurbriggen, Pevion Biotech, Switzerland; Adrian Hill, University of Oxford, UK; Alan Thomas and Ed Remarque, Biomedical Primate Research Centre, The Netherlands; David Cavanagh, University of Edinburgh, UK; Robert Sauerwein, Radboud University Nijmegen Medical Centre, The Netherlands; Anthony Holder, National Institute for Medical Research, UK; Ramadhani Noor, African Malaria Network Trust, Tanzania; Gerd Pluschke, Swiss Tropical Institute, Switzerland; Klavs Berzin, Stockholm University, Sweden; Francois Spertini, Centre Hospitalier Universitaire Vaudois, Switzerland; Benjamin Mordmüller, Eberhard-Karls Universität Tübingen, Germany; Reinhard Glück, Etna Biotech, Italy; Hermann Bujard, Ruprecht-Karls-Universität Heidelberg, Germany; and Michael Theisen, Statens Serum Institut, Denmark.

\section{Author details}

${ }^{1}$ European Vaccine Initiative, UniversitätsKlinikum Heidelberg, Im Neuenheimer Feld 326, 69120 Heidelberg, Germany. ${ }^{2}$ MRC National Institute for Medical Research, Division of Parasitology, The Ridgeway, Mill Hill, London NW7 1AA, UK. ${ }^{3}$ University of Oxford, Jenner Institute, Old Road Campus Research Building, Roosevelt Drive, Oxford, OX3 7DQ, UK.

${ }^{4}$ Copenhagen University, Centre for Medical Parasitology, Bartholinsgade 2,

1356 Copenhagen K, Denmark.

\section{Authors' contributions}

$R L T$, project manager of the EMVDA project, has coordinated and contributed to the writing of the manuscript. OL, coordinator of the EMVDA project and $\mathrm{EBI}$, clinical trial director, have contributed to the writing of the manuscript. AAH, AVSH and DEA have participated in a number of ECfunded malaria vaccine development projects and have contributed to the writing of the manuscript. All authors read and approved the final manuscript.

\section{Competing interests}

The authors declare that they have no competing interests.

Received: 14 July 2011 Accepted: 1 September 2011

Published: 1 September 2011

\section{References}

1. European Commission, Research, Health, Infectious Diseases. [http://ec. europa.eu/research/health/infectious-diseases/poverty-diseases/index_en. html]

2. World Health Organization, Malaria. [http://www.who.int/topics/malaria/ en].

3. European Malaria Vaccine Development Association. [http://www.emvda. org].

4. Roll Back Malaria. [http://www.rbm.who.int].

5. Cohen J, Nussenzweig V, Nussenzweig R, Vekemans J, Leach A: From the circumsporozoite protein to the RTS, S/AS candidate vaccine. Human Vaccine 2010, 6:90-96.

6. Medaglini D, Hoeveler A: The European research effort for HIV/AIDS, malaria and tuberculosis. Vaccine 2003, 21:116-120.

7. Olesen OF, Lonnroth A, Mulligan B: Human vaccine research in the European Union. Vaccine 2009, 27:640-645.

doi:10.1186/1475-2875-10-255

Cite this article as: Thøgersen et al:: Comparative decline in funding of European Commission malaria vaccine projects: what next for the European scientists working in this field? Malaria Journal 2011 10:255 